\title{
Determinants of glucose tolerance in impaired glucose tolerance at baseline in the Actos Now for Prevention of Diabetes (ACT NOW) study
}

\author{
R. A. DeFronzo • M. A. Banerji • G. A. Bray • T. A. Buchanan • \\ S. Clement • R. R. Henry • A. E. Kitabchi • S. Mudaliar • N. Musi • \\ R. Ratner $\cdot$ P. Reaven $\cdot$ D. C. Schwenke $\cdot$ F. D. Stentz $\cdot$ D. Tripathy $\cdot$ \\ for the ACT NOW Study Group
}

Received: 5 May 2009/Accepted: 20 October 2009/Published online: 10 December 2009

(C) Springer-Verlag 2009

\begin{abstract}
Aims/hypothesis The aim of the study was to examine the determinants of oral glucose tolerance in 602 persons with impaired glucose tolerance (IGT) who participated in the Actos Now for Prevention of Diabetes (ACT NOW) study. Methods In addition to the 602 IGT participants, 115 persons with normal glucose tolerance (NGT) and 50 with impaired fasting glucose (IFG) were identified during screening and included in this analysis. Insulin secretion
\end{abstract}

Electronic supplementary material The online version of this article (doi:10.1007/s00125-009-1614-2) contains supplementary material, which is available to authorised users.

R. A. DeFronzo $(\bowtie) \cdot N$. Musi $\cdot$ D. Tripathy

Diabetes Division, University of Texas Health Science Center,

7703 Floyd Curl Drive,

San Antonio, TX 78229, USA

e-mail: albarado@uthscsa.edu

M. A. Banerji

SUNY Health Science Center at Brooklyn,

Brooklyn, NY, USA

G. A. Bray

Pennington Biomedical Research Center

and Louisiana State University,

Baton Rouge, LA, USA

T. A. Buchanan

Keck School of Medicine, University of Southern California,

Los Angeles, CA, USA

\section{S. Clement}

Division of Endocrinology and Metabolism,

Georgetown University,

Washington, DC, USA and insulin sensitivity indices were derived from plasma glucose and insulin during an OGTT. The acute insulin response (AIR) (0-10 $\mathrm{min}$ ) and insulin sensitivity $\left(\mathrm{S}_{\mathrm{I}}\right)$ were measured with the frequently sampled intravenous glucose tolerance test (FSIVGTT) in a subset of participants.

Results At baseline, fasting plasma glucose, $2 \mathrm{~h}$ postprandial glucose (OGTT) and $\mathrm{HbA}_{1 \mathrm{c}}$ were $5.8 \pm 0.02 \mathrm{mmol} / \mathrm{l}$, $10.5 \pm 0.05 \mathrm{mmol} / 1$ and $5.5 \pm 0.04 \%$, respectively, in participants with IGT. Participants with IGT were characterised

R. R. Henry $\cdot$ S. Mudaliar

VA San Diego Healthcare System

and University of California at San Diego,

San Diego, CA, USA

\section{A. E. Kitabchi • F. D. Stentz}

Division of Endocrinology, Diabetes,

and Metabolic Diseases,

University of Tennessee,

Memphis, TN, USA

\section{R. Ratner}

Medstar Research Institute,

Hyattsville, MD, USA

P. Reaven

Phoenix VA Health Care System,

Phoenix, AZ, USA

D. C. Schwenke

W. P. Carey School of Business,

Arizona State University,

Tempe, AZ, USA 
by defects in early $\left(\Delta I_{0-30} / \Delta G_{0-30} \times\right.$ Matsuda index, where $\Delta I$ is change in insulin in the first $30 \mathrm{~min}$ and $\Delta G$ is change in glucose in the first $30 \mathrm{~min})$ and total $\left(\Delta \mathrm{I}_{0-120} / \Delta \mathrm{G}_{0-120} \times\right.$ Matsuda index) insulin secretion and in insulin sensitivity (Matsuda index and $\mathrm{S}_{\mathrm{I}}$ ). Participants with IGT in whom $2 \mathrm{~h}$ plasma glucose was $7.8-8.3 \mathrm{mmol} / \mathrm{l}$ had a $63 \%$ decrease in the insulin secretion/insulin resistance (disposition) index vs participants with NGT and this defect worsened progressively as $2 \mathrm{~h}$ plasma glucose rose to $8.9-9.94 \mathrm{mmol} / \mathrm{l}$ (by $73 \%$ ) and $10.0-11.05 \mathrm{mmol} / 1$ (by $80 \%$ ). The Matsuda insulin sensitivity index was reduced by $40 \%$ in IGT compared with NGT ( $p<$ 0.005 ). In multivariate analysis, beta cell function was the primary determinant of glucose AUC during OGTT, explaining $62 \%$ of the variance.

Conclusion Our results strongly suggest that progressive beta cell failure is the main determinant of progression of NGT to IGT.

Keywords ACT NOW - Insulin resistance $\cdot$ Insulin secretion $\cdot$ Impaired glucose tolerance $\cdot$ Impaired fasting glucose $\cdot$ Normal glucose tolerance $\cdot$ Type 2 diabetes pathogenesis

$\begin{array}{ll}\text { Abbreviations } \\ \text { ACT NOW } & \text { Actos Now for Prevention of Diabetes } \\ \text { AIR } & \text { Acute insulin response } \\ \text { FPG } & \text { Fasting plasma glucose } \\ \text { FPI } & \text { Fasting plasma insulin } \\ \text { FSIVGTT } & \begin{array}{l}\text { Frequently sampled intravenous glucose } \\ \text { tolerance test }\end{array} \\ & \text { Impaired fasting glucose } \\ \text { IFG } & \text { Impaired glucose tolerance } \\ \text { IGT } & \text { Insulin resistance } \\ \text { IR } & \text { Insulin secretory rate } \\ \text { ISR } & \text { Normal glucose tolerance } \\ \mathrm{NGT}_{\mathrm{G}} & \text { Glucose sensitivity } \\ \mathrm{S}_{\mathrm{G}} & \text { Insulin sensitivity } \\ \mathrm{S}_{\mathrm{I}} & \end{array}$

\section{Introduction}

Type 2 diabetes mellitus affects 21 million Americans [1] and its prevalence is rapidly increasing [2]. Microvascular and macrovascular [3] complications are common in type 2 diabetes and are related to the severity/duration of hyperglycaemia [4].

The natural history of type 2 diabetes has been well defined $[5,6]$; it starts with a genetic predisposition and progresses from normal glucose tolerance (NGT) with insulin resistance to impaired glucose tolerance (IGT) with superimposition of beta cell failure on insulin resistance, and eventually to type 2 diabetes.
Because hyperglycaemia plays a central role in the development of micro- and macrovascular complications $[3,4]$, it follows that interventions that prevent or delay the onset of hyperglycaemia would be effective in preventing long-term complications. Lifestyle modification [7, 8] and medical therapy with metformin [8], thiazolidinediones [911] and acarbose [12] can prevent or delay the onset of type 2 diabetes in high-risk persons. IGT represents a high-risk group, with type 2 diabetes conversion rates varying from $3 \%$ to $13 \%$ per year [13]. Most previous studies have not characterised the pathophysiological disturbances responsible for IGT [7, 9, 11, 12] or have employed simplistic measures of beta cell function and insulin resistance $[8,14]$. Where more sophisticated measures were employed, sample size was small [10]. Here we report the assessment of beta cell function and insulin sensitivity in 602 people with IGT at baseline in the Actos Now for Prevention of Diabetes (ACT NOW) study. This represents the largest IGT cohort employing sophisticated measures of beta cell function and insulin sensitivity to characterise core defects responsible for type 2 diabetes.

\section{Methods}

Participants Of 1,850 individuals at eight US centres screened with an OGTT, 602 had IGT (fasting plasma glucose $[\mathrm{FPG}]<7.0 \mathrm{mmol} / \mathrm{l}, 2 \mathrm{~h}$ plasma glucose 7.8 $11.05 \mathrm{mmol} / \mathrm{l})$ [15]. All participants with IGT had FPG 5.28-6.94 mmol/1, BMI $\geq 25 \mathrm{~kg} / \mathrm{m}^{2}$, age $\geq 18$ years and at least one other high-risk characteristic: (1) at least one component of metabolic syndrome; (2) family history of type 2 diabetes; (3) gestational diabetes; (4) polycystic ovarian syndrome; (5) minority ethnicity. Of the 1,850 individuals screened, $\sim 1,050$ did not qualify because of laboratory abnormalities or exclusion criteria. The remaining 800 participants underwent an OGTT and, based on the OGTT results, 602 were randomised for treatment. One hundred and fifteen NGT and 50 IFG participants were identified and were included [15]. All participants gave informed consent to participation in the study. The study protocol was approved by the institutional review board of each institution and the investigations were carried out in accordance with the Declaration of Helsinki.

Participants received a $75 \mathrm{~g}$ OGTT at 08:00 hours after an overnight fast. Samples were drawn at $-30,-15,0$ and every $15 \mathrm{~min}$ for $2 \mathrm{~h}$ for plasma glucose, insulin, C-peptide and NEFA. Participants with FPG $\geq 5.3$ and $<7.0 \mathrm{mmol} / 1$ and $2 \mathrm{~h}$ plasma glucose $7.8-11.05 \mathrm{mmol} / \mathrm{l}$ returned for medical history, physical examination, blood chemistry, complete blood count, $\mathrm{HbA}_{1 \mathrm{c}}$, fasting lipids, urinalysis and an electrocardiogram. Blood pressure was measured with a Dinamap Pro 100 (GE Healthcare, Waukesha, WI, USA) 
after 5 min of reclining. Body weight was measured on a digital scale (Health-O-Meter, Bridgeview, IL, USA) and height was recorded. Waist circumference was measured using a Gulick II Tape Measure at the midpoint between highest point at the iliac crest and the lowest part of the costal margin in the midaxillary line. Participants at four centres $(n=376)$ returned for FSIVGTT [16].

Measurements Plasma glucose was measured by the glucose oxidase reaction, plasma insulin by radioimmunoassay (Diagnostic Products, Los Angeles, CA, USA) (inter-assay and intra-assay $\mathrm{CV} 7.1 \%$ and $5.1 \%$ respectively), plasma C-peptide by radioimmunoassay (Diagnostic Systems, Webster, TX, USA) (inter-assay and intra-assay CV 4.3\% and $2.4 \%$, respectively) and $\mathrm{HbA}_{1 \mathrm{c}}$ with a DCA 2000 analyser (Bayer, Leverkusen, Germany). Total plasma cholesterol and triacylglycerol were measured using the cholesterol oxidase-dimethyoxyaniline (CHOD-DAOS) method (Wako, Richmond, VA, USA) and an enzymatic assay (Stanbio Laboratory, Boerne, TX, USA). HDL-cholesterol was measured after precipitation of apolipoprotein B-containing lipoproteins, using the CHOD-DAOS method (Wako). LDLcholesterol was calculated using the Friedewald equation.

Calculations The incremental AUC for plasma glucose and insulin during the OGTT was calculated according to the trapezoidal rule. The primary stimulus for insulin secretion is the increment in plasma glucose, and the insulinogenic index was calculated as the change in insulin concentration $(\Delta \mathrm{I})($ AUC) divided by the change in glucose concentration $(\triangle \mathrm{G})$ (AUC) from 0 to $30 \mathrm{~min}$ and from 0 to $120 \mathrm{~min}$. The insulin secretory rate (ISR) was calculated by plasma Cpeptide deconvolution [17].

During the FSIVGTT, first-phase insulin secretion was calculated as the increment in plasma insulin (AUC) from 0 to $10 \mathrm{~min}$. Insulin sensitivity $\left(\mathrm{S}_{\mathrm{I}}\right)$ and glucose sensitivity $\left(\mathrm{S}_{\mathrm{G}}\right)$ were determined from the FSIVGTT [16]. Insulin sensitivity during OGTT was calculated from the Matsuda index [18].

The insulin secretion/insulin resistance (IS/IR) (disposition) index during OGTT was calculated as $\Delta \mathrm{I} / \Delta \mathrm{G} \times$ Matsuda index $[19,20], \Delta \mathrm{ISR} / \Delta \mathrm{G} \times$ Matsuda index, $\Delta \mathrm{I} / \Delta \mathrm{G} \times \mathrm{S}_{\mathrm{I}}$ and $\Delta \mathrm{ISR} / \Delta \mathrm{G} \times \mathrm{S}_{\mathrm{I}}$. All beta cell function measures yielded similar results. The hepatic insulin resistance index was calculated as FPI $\times$ FPG, since HGP suppression is linearly related $(r=$ $0.92, p<0.001)$ to the plasma insulin concentration over the FPI range from $42 \pm 7$ to $69 \pm 14$ to $153 \pm 14 \mathrm{pmol} / 1$ [21]. The basal adipocyte insulin resistance index was calculated as FPI $\times$ fasting plasma NEFA because there is a linear decline in plasma NEFA over the FPI range from $42 \pm 7$ to $69 \pm 14$ to $153 \pm 14 \mathrm{pmol} / 1(r=0.94, p<0.001)[21]$.

Statistical analysis Data are presented as mean \pm SEM. For analysis, IGT participants were divided into tertiles based upon $2 \mathrm{~h}$ plasma glucose during the OGTT $(7.8-8.83,8.9$ 9.94, $10.0-11.05 \mathrm{mmol} / \mathrm{l})$. Pearson's correlation was used to assess relationships between variables. To compare the mean between groups, ANOVA was used; significance was adjusted by Bonferroni correction. Significance was accepted at $p<0.05$. Assessment of the contribution of multiple factors to measured variables was performed by stepwise multivariate analysis including continuous (age, BMI, FPG, 2 h plasma glucose, etc.) and categorical (sex, diabetes family history, ethnicity) variables.

\section{Results}

Anthropometric, clinical and metabolic characteristics (Table 1) The mean age of IGT participants was $52.3 \pm$ 0.5 years, women outnumbered men $(59 \%$ vs $41 \%)$ and BMI was $34.3 \pm 0.4 \mathrm{~kg} / \mathrm{m}^{2} ; 10.5 \%$ had BMI $<27.5 \mathrm{~kg} / \mathrm{m}^{2}$, $15.5 \%$ had BMI $27.5-30.0 \mathrm{~kg} / \mathrm{m}^{2}$ and $74 \%$ had BMI $>30.0 \mathrm{~kg} / \mathrm{m}^{2}$. Waist circumference was $104 \pm 0.7 \mathrm{~cm}$ in women and $111 \pm 0.8 \mathrm{~cm}$ in men. Forty-eight per cent had at least one first-degree relative with type 2 diabetes. Gestational diabetes mellitus and polycystic ovarian syndrome were present in $16 \%$ and $4 \%$, respectively. Twentyfive per cent of IGT participants had plasma triacylglycerol $>1.76 \mathrm{mmol} / \mathrm{l}$. HDL-cholesterol was reduced in $55 \%$ of men $(<1.04 \mathrm{mmol} / \mathrm{l})$ and $67 \%$ of women $(<1.3 \mathrm{mmol} / \mathrm{l})$. LDL-cholesterol was elevated $(>2.59 \mathrm{mmol} / \mathrm{l})$ in $40 \%$ of participants with IGT. Systolic and diastolic blood pressures were elevated ( $>135$ and $>85 \mathrm{mmHg}$ respectively) in $44 \%$ and $12 \%$ of IGT participants respectively. All groups were well matched for BMI.

Glycaemic measures (Table 1) Mean $\mathrm{HbA}_{1 \mathrm{c}}$ was $5.50 \pm$ $0.04 \%$ in participants with IGT and $14 \%$ had $\mathrm{HbA}_{1 \mathrm{c}} \geq 6 \%$. Sixty-eight per cent had IFG. The percentage of IGT participants with $2 \mathrm{~h}$ plasma glucose 7.8-8.83, 8.9-9.94 and $10.0-11.05 \mathrm{mmol} / 1$ was 38,33 and $29 \%$ respectively. Of the 602 participants, 195 (32\%) had isolated IGT and 407 (68\%) had combined IFG and IGT. Compared with 115 age/sex/obesity-matched participants with NGT, participants with IGT had higher FPG, $2 \mathrm{~h}$ plasma glucose and mean plasma glucose during the OGTT (all $p<0.005$ ) (Table 1 and Fig. 1). During screening, 50 participants with isolated IFG were identified [3]. Participants with IFG and IGT had similar FPG, but the $2 \mathrm{~h}$ plasma glucose and mean (0-120 min) plasma glucose during the OGTT were decreased in IFG compared with participants with IGT.

Beta cell function Compared with participants with NGT, those with IGT had higher fasting, $2 \mathrm{~h}$ and mean plasma insulin concentrations (OGTT) (all $p<0.005)$ (Table 1 and Fig. 1). The incremental plasma insulin response (AUC) 
Table 1 Clinical anthropometric, laboratory and metabolic data

\begin{tabular}{|c|c|c|c|c|c|c|}
\hline Variable & $\begin{array}{l}\text { Total IGT }{ }^{\mathrm{a}} \\
(n=602)\end{array}$ & $\begin{array}{l}\text { IGT with IFG } \\
(n=407)\end{array}$ & $\begin{array}{l}\text { Isolated IGT } \\
(n=195)\end{array}$ & $\begin{array}{l}\text { Isolated IFG } \\
(n=50)\end{array}$ & $\begin{array}{l}\text { NGT } \\
(n=115)\end{array}$ & $p$ value \\
\hline Age (years) & $52.3 \pm 0.5$ & $53.2 \pm 0.6^{*}$ & $50.4 \pm 0.9$ & $48.0 \pm 0.9$ & $42.8 \pm 1.3$ & \\
\hline Sex (male/female) & $253(41 \%) / 349(59 \%)$ & & & & & \\
\hline Ethnicity (E/MA/AA/O) & $(327 / 154 / 101 / 20)$ & & & & & \\
\hline Positive family history $(n, \%)$ & $289(48 \%)$ & & & & & \\
\hline BMI $\left(\mathrm{kg} / \mathrm{m}^{2}\right)$ & $34.3 \pm 0.4$ & $34.6 \pm 0.3$ & $33.8 \pm 0.4$ & $33.0 \pm 1.5$ & $33.7 \pm 0.4$ & \\
\hline \multicolumn{7}{|l|}{ Waist circumference $(\mathrm{cm})$} \\
\hline Male & $111 \pm 0.8$ & $112 \pm 0.9$ & $110 \pm 2$ & & & \\
\hline Female & $104 \pm 0.7$ & $104 \pm 0.9$ & $101 \pm 1.1$ & & & \\
\hline LDL-cholesterol (mmol/l) & $2.74 \pm 0.05$ & $2.74 \pm 0.08$ & $2.74 \pm 0.05$ & & & \\
\hline HDL-cholesterol (mmol/l) & $1.04 \pm 0.001$ & $1.04 \pm 0.001$ & $1.08 \pm 0.002$ & & & \\
\hline Triacylglycerol (mmol/l) & $1.4 \pm 0.03$ & $1.45 \pm 0.04$ & $1.29 \pm 0.04$ & & & \\
\hline Systolic BP (mm/Hg) & $128 \pm 0.7$ & $128 \pm 0.7$ & $127 \pm 1.2$ & & & \\
\hline Diastolic BP (mm/Hg) & $74 \pm 0.4$ & $74 \pm 0.5$ & $73 \pm 0.7$ & & & \\
\hline $\mathrm{HbA}_{1 \mathrm{c}}(\%)$ & $5.50 \pm 0.04$ & $5.60 \pm 0.03^{*}$ & $5.36 \pm 0.02$ & $5.14 \pm 0.08$ & $5.27 \pm 0.9$ & $<0.005$ \\
\hline FPG $(\mathrm{mmol} / \mathrm{l})$ & $5.83 \pm 0.02$ & $6.00 \pm 0.02 *$ & $5.38 \pm 0.02$ & $5.89 \pm 0.03$ & $5.11 \pm 0.04$ & $<0.005$ \\
\hline \multicolumn{7}{|l|}{ OGTT } \\
\hline Mean plasma glucose $(\mathrm{mmol} / \mathrm{l})$ & $9.5 \pm 0.04$ & $9.72 \pm 0.05^{*}$ & $8.96 \pm 0.05$ & $8.1 \pm 0.02$ & $6.94 \pm 0.11$ & $<0.005$ \\
\hline $2 \mathrm{~h}$ plasma glucose $(\mathrm{mmol} / \mathrm{l})$ & $10.5 \pm 0.05$ & $9.4 \pm 0.05^{*}$ & $9.10 \pm 0.05$ & $6.7 \pm 0.11$ & $6.0 \pm 0.11$ & $<0.005$ \\
\hline FPI (pmol/l) & $64 \pm 2.4$ & $68 \pm 2.4^{*}$ & $55 \pm 4$ & $44 \pm 5.4$ & $44 \pm 4.2$ & $<0.005$ \\
\hline \multicolumn{7}{|l|}{ OGTT } \\
\hline $30 \min$ PI (pmol/l) & $342 \pm 12$ & $348 \pm 12$ & $336 \pm 18$ & $348 \pm 30$ & $180 \pm 18$ & NS \\
\hline Mean PI (pmol/l) & $426 \pm 12$ & $432 \pm 12 *$ & $414 \pm 18$ & $402 \pm 36$ & $354 \pm 12$ & 0.02 \\
\hline \multicolumn{7}{|l|}{ NEFA $(\mu \mathrm{mol} / 1)$} \\
\hline Fasting & $540 \pm 8$ & $531 \pm 12$ & $560 \pm 11$ & $560 \pm 21$ & $574 \pm 14$ & NS \\
\hline Mean-OGTT & $269 \pm 5$ & $267 \pm 6$ & $274 \pm 8$ & $270 \pm 18$ & $262 \pm 10$ & NS \\
\hline
\end{tabular}

Values are mean \pm SEM or $n(\%)$

${ }^{\text {a }}$ The 602 participants (column 1) represent the sum of the 407 participants with combined IGT plus IFG (column 2) and the 195 participants with isolated IGT (column 3)

$* p<0.05$ vs NGT

AA, African-American; E, Europid; MA, Mexican-American; O, other; PI, plasma insulin

during the OGTT was slightly higher in IGT $(n=602)$ than in NGT $(n=115)$. The 30 min plasma insulin concentration during the OGTT was similar (NS) whereas mean plasma insulin $(0-120 \mathrm{~min})$ was higher in IGT than in NGT $(p=$ 0.02) (Table 1). In IFG, the $30 \mathrm{~min}$ and mean (0-120 min) plasma insulin concentrations during the OGTT were not different from those in NGT (Table 1 and Fig. 1b). Both early $\left(\Delta \mathrm{I}_{0-30} / \Delta \mathrm{G}_{0-30}\right)$ and total $\left(\Delta \mathrm{I}_{0-120} / \Delta \mathrm{G}_{0-120}\right)$ plasma insulin responses were reduced $(p<0.001$, Table 2$)$ in IGT compared with NGT. Similarly, $\Delta \mathrm{ISR} / \Delta \mathrm{G}$ was reduced by $50 \%$ in IGT $(n=602)$ compared with NGT $(p<0.005$; Electronic supplementary material [ESM] Fig. 1b). Impaired beta cell function in IGT is more evident when IS/IR indices $(\Delta \mathrm{I} / \Delta \mathrm{G} \times$ Matsuda index $[60 \%$ decrease] and $\Delta \mathrm{ISR} /$ $\Delta \mathrm{G} \times$ Matsuda index [68\% decrease]) are calculated (Table 2 and Fig. 2b; ESM Fig. 1c). Impaired insulin secretion $(\Delta \mathrm{I} /$
$\Delta \mathrm{G} \times$ Matsuda index and $\Delta \mathrm{ISR} / \Delta \mathrm{G} \times$ Matsuda index) was more severe in combined IGT/IFG than in isolated IGT $(p<$ 0.01) (Table 2, Fig. 2 and ESM Fig. 1).

IGT participants with $2 \mathrm{~h}$ plasma glucose $7.8-8.3 \mathrm{mmol} /$ 1 had a $63 \%$ decrease in the IS/IR index compared with NGT; this defect worsened progressively as $2 \mathrm{~h}$ plasma glucose increased to $8.9-9.94 \mathrm{mmol} / 1$ (by $73 \%$ ) and 10.0 $11.05 \mathrm{mmol} / \mathrm{l}$ (by 80\%) (Fig. 3b, c). The progressive decline in beta cell function is clearly apparent if the $\log _{e}$ of the IS/IR index is plotted against the $\log _{e}$ of $2 \mathrm{~h}$ plasma glucose (Fig. 3d) and the $\log _{e}$ of FPG (Fig. 2d).

In participants with IFG, $\Delta \mathrm{I} / \Delta \mathrm{G} \times$ Matsuda index at $30 \mathrm{~min}$ was reduced by $41 \%(p<0.005)$ compared with participants with NGT (Fig. 2 and Table 2). $\Delta \mathrm{ISR}_{0-120}$ and $\Delta \mathrm{ISR}_{0-120} / \Delta \mathrm{G}_{0-120}$ were similar in IFG and NGT, whereas $\Delta \mathrm{ISR} / \Delta \mathrm{G} \times$ Matsuda index from 0 to $120 \mathrm{~min}$ (by $11 \%$ ) and 

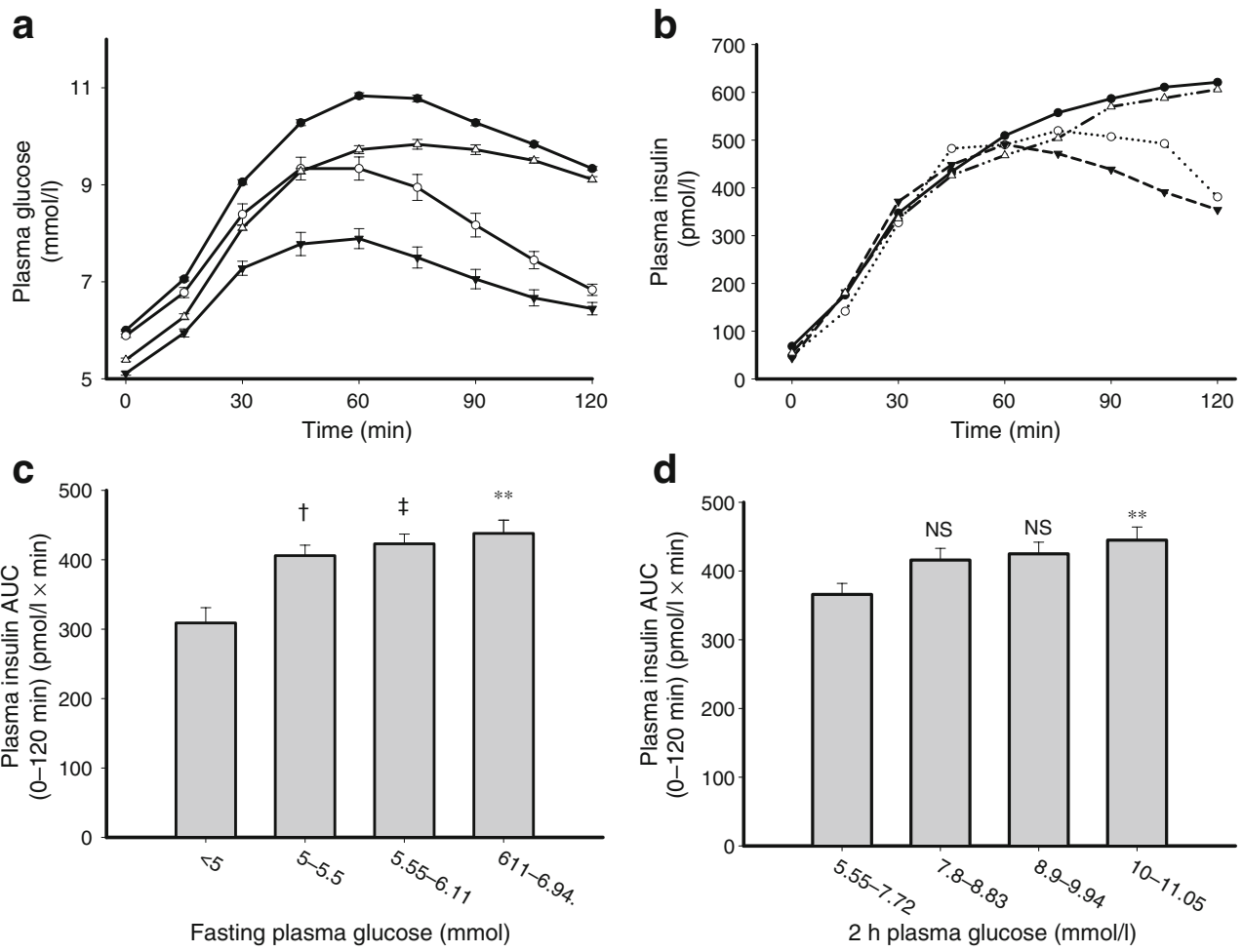

Fig. 1 Plasma glucose (a) and insulin (b) concentrations during the OGTT. Relationship between the mean plasma insulin concentration during OGTT and $2 \mathrm{~h}(\mathbf{d})$ and fasting (c) plasma glucose concentrations

during the OGTT. White circles, IFG; black circles, IFG+IGT; white triangles, IG; black triangles, NGT. ${ }^{* *} p=0.01,{ }^{\star} p=0.02,{ }^{\dagger} p=0.09$

from 60 to 120 min (by $27 \%$ ) was slightly decreased in IFG compared with NGT; all beta cell function indices were significantly lower in IGT than in IFG (Table 2).

The acute insulin response $(0-10 \mathrm{~min})$ during the FSIVGTT was decreased in combined IGT/IFG compared with isolated IGT $(2,306 \pm 125$ vs $2,993 \pm 180, p=0.003)$ (Table 2). The IS/IR index (acute insulin response $[\mathrm{AIR}] \times \mathrm{S}_{\mathrm{I}}$ calculated from FSIVGTT) was also reduced in combined IGT/IFG compared with isolated IGT $(5,285 \pm 298$ vs $6,931 \pm$ $576, p<0.006$ ) (Table 2). The FSIVGTT was not performed in NGT or IFG.

Insulin sensitivity indices The Matsuda insulin sensitivity index was reduced by $40 \%$ in IGT compared with NGT ( $p<$ 0.005 ) (Table 2). The greater part of the decline in Matsuda index occurred during transition from NGT $(2 \mathrm{~h}$ plasma glucose $6.67-7.7 \mathrm{mmol} / \mathrm{l})$ to IGT ( $2 \mathrm{~h}$ plasma glucose 7.8 $8.83 \mathrm{mmol} / \mathrm{l}$ ) (ESM Fig. 3). The $\mathrm{S}_{\mathrm{I}}$ was $0.502 \pm 0.03 \mathrm{~min}^{-1}$ $(\mathrm{pmol} / \mathrm{l})^{-1} \times 10^{-4}$; participants with NGT and IFG did not receive the FSIVGTT. Compared with NGT $(1.17 \pm 0.08 \%)$ in previous publications [4, 5], $\mathrm{S}_{\mathrm{I}}$ was reduced in participants with IGT. Within IGT subgroups $(2 \mathrm{~h}$ plasma glucose $7.8-8.83,8.9-9.91$ and $10.0-11.05 \mathrm{mmol} / \mathrm{l}), \mathrm{S}_{\mathrm{I}}$ was similarly reduced: $0.47 \pm 0.03,0.45 \pm 0.03$ and $0.47 \pm 0.03$ $\min ^{-1}(\mathrm{pmol} / 1)^{-1} \times 10^{-4}(\mathrm{NS})$. There was no difference in $\mathrm{S}_{\mathrm{I}}$

between IGT and combined IGT/IFG. In IGT, $\mathrm{S}_{\mathrm{I}}$ (FSIVGTT) correlated with the Matsuda index $(r=0.514$, $p<0.0001)$.

Hepatic and adipocyte insulin sensitivity Hepatic insulin resistance was increased by $62 \%$ and $24 \%$ in IGT $(n=602)$ and IFG compared with NGT (both $p<0.005$ ) (Table 2), and in IGT it increased progressively by $25 \%, 70 \%$ and $110 \%$ (all $p<0.005$ ) as FPG increased from 5.3 to 5.5, from 5.55 to 6.05 and from 6.11 to $6.94 \mathrm{mmol} / \mathrm{l}$. Adipocyte insulin resistance was $62 \%$ higher in IGT than in NGT $(p<$ 0.001 ), with greater severity in combined IGT/IFG vs isolated IGT (Table 2). In IGT, adipocyte insulin resistance increased from $34 \pm 2$ to $36 \pm 2$ to $39.6 \pm 1.5 \mathrm{pmol} / 1 \times \mathrm{mmol} /$ 1 as $2 \mathrm{~h}$ plasma glucose increased from $7.8-8.83$ to $8.9-9.94$ and $10.0-11.05 \mathrm{mmol} / \mathrm{l}(p<0.01$ for trend).

Glucose sensitivity $\mathrm{S}_{\mathrm{G}}$ in IGT $(0.013 \pm 0.0003)$ was reduced compared with NGT $(0.0260 \pm 0.0028)$ in previous reports $[22,23]$.

Correlations between $2 \mathrm{~h}$ plasma glucose and insulin secretion (ESM Table 1) The $2 \mathrm{~h}$ plasma glucose during OGTT was strongly correlated with the IS/IR index $(\Delta \mathrm{I} /$ $\Delta \mathrm{G} \times$ Matsuda index) within the combined NGT/IGT 
Table 2 Indices of beta cell function and insulin sensitivity

\begin{tabular}{|c|c|c|c|c|c|c|}
\hline & $\begin{array}{l}\text { Total IGT }{ }^{\mathrm{a}} \\
(n=602)\end{array}$ & $\begin{array}{l}\text { IGT with IFG } \\
(n=407)\end{array}$ & $\begin{array}{l}\text { Isolated IGT } \\
(n=195)\end{array}$ & $\begin{array}{l}\text { Isolated IFG } \\
(n=50)\end{array}$ & $\begin{array}{l}\text { NGT } \\
(n=115)\end{array}$ & $p$ value $^{\mathrm{b}}$ \\
\hline \multicolumn{7}{|l|}{ Insulin secretion } \\
\hline$\Delta \mathrm{I}(\mathrm{AUC})-\mathrm{OGTT}(\mathrm{pmol} / 1 \times \mathrm{h})$ & $744 \pm 18$ & $750 \pm 18$ & $744 \pm 30$ & $744 \pm 66$ & $660 \pm 30$ & NS \\
\hline$\Delta \mathrm{G}(\mathrm{AUC})-\mathrm{OGTT}(\mathrm{mmol} / \mathrm{l} \times \mathrm{h})$ & $6.9 \pm 0.05$ & $6.94 \pm 0.11$ & $6.61 \pm 0.16$ & $4.33 \pm 0.3$ & $3.67 \pm 0.2$ & $<0.0005$ \\
\hline $\mathrm{I}_{0-30} / \Delta \mathrm{G}_{0-30}(\mathrm{pmol} / \mathrm{mmol})$ & $119 \pm 31$ & $113 \pm 5.2$ & $130 \pm 7.8$ & $126 \pm 37$ & $171 \pm 16$ & 0.01 \\
\hline$\Delta \mathrm{I}_{0-120} / \Delta \mathrm{G}_{0-120}(\mathrm{pmol} / \mathrm{mmol})$ & $114 \pm 3.1$ & $113 \pm 5.2$ & $115 \pm 5.2$ & $190 \pm 20$ & $205 \pm 14$ & $<0.005$ \\
\hline$\Delta \mathrm{I}_{60-120} / \Delta \mathrm{G}_{60-120}(\mathrm{pmol} / \mathrm{mmol})$ & $56 \pm 1.4$ & $55 \pm 1.6$ & $57 \pm 2.6$ & $67 \pm 4$ & $74 \pm 6.2$ & $<0.005$ \\
\hline$\Delta \mathrm{I}_{0-30} / \Delta \mathrm{G}_{0-30} \times$ Matsuda index $(\mathrm{pmol} / \mathrm{mmol})$ & $1,073 \pm 39$ & $951 \pm 57$ & $1,439 \pm 93$ & $1,565 \pm 221$ & $2,324 \pm 142$ & $<0.005$ \\
\hline$\Delta \mathrm{I}_{0-120} / \Delta \mathrm{G}_{0-120} \times$ Matsuda index $(\mathrm{pmol} / \mathrm{mmol})$ & $1,012 \pm 23$ & $913 \pm 24$ & $1,218 \pm 45$ & $2,256 \pm 246$ & $3,186 \pm 228$ & $<0.005$ \\
\hline$\Delta \mathrm{I}_{60-120} / \Delta \mathrm{G}_{60-120} \times$ Matsuda index $(\mathrm{pmol} / \mathrm{mmol})$ & $477 \pm 7.0$ & $433 \pm 7$ & $516 \pm 14$ & $735 \pm 11$ & $1,037 \pm 51$ & $<0.005$ \\
\hline$\Delta \mathrm{I}_{0-30} / \Delta \mathrm{G}_{0-30} \times \mathrm{S}_{\mathrm{I}}(\mathrm{pmol} / \mathrm{mmol})$ & $0.421 \pm 0.02$ & $0.405 \pm 0.02$ & $0.450 \pm 0.03$ & - & - & \\
\hline$\Delta \mathrm{I}_{0-120} / \Delta \mathrm{G}_{0-120} \times \mathrm{S}_{\mathrm{I}}(\mathrm{pmol} / \mathrm{mmol})$ & $0.437 \pm 0.02$ & $0.449 \pm 0.03$ & $0.412 \pm 0.03$ & - & - & \\
\hline $\mathrm{AIR}_{0-10}$ & $2,507 \pm 104$ & $2,306 \pm 125$ & $2,993 \pm 180$ & & & 0.003 \\
\hline $\mathrm{AIR} \times \mathrm{S}_{\mathrm{I}}(\mathrm{FSIVGTT})$ & $5,757 \pm 285$ & $5,285 \pm 298$ & $6,931 \pm 576$ & & & 0.006 \\
\hline \multicolumn{7}{|l|}{ Insulin sensitivity } \\
\hline \multicolumn{7}{|l|}{ Whole body } \\
\hline Matsuda index & $11.3 \pm 0.3$ & $13.4 \pm 0.6$ & $10.2 \pm 0.6$ & $14.6 \pm 1.3$ & $18.3 \pm 0.9$ & $<0.005$ \\
\hline $\mathrm{S}_{\mathrm{I}}\left(\mathrm{min}^{-1}[\mathrm{pmol} / 1]^{-1} \times 10^{-4}\right)$ & $0.502 \pm 0.03$ & $0.519 \pm 0.03$ & $0.459 \pm 0.03$ & & & \\
\hline Liver $(\mathrm{FPI} \times \mathrm{FPG})(\mathrm{pmol} \times \mathrm{mmol} / \mathrm{l})$ & $381 \pm 13$ & $422 \pm 15$ & $299 \pm 31$ & $291 \pm 31$ & & \\
\hline Adipocytes $($ FPI $\times$ F-NEFA $)(p m o l \times m m o l / 1)$ & $36 \pm 1.3$ & $38 \pm 1.7$ & $32 \pm 2.5$ & $29 \pm 3.5$ & $24 \pm 1.7$ & $<0.005$ \\
\hline
\end{tabular}

${ }^{a}$ The 602 IGT participants represent the sum of the 407 participants with combined IGT plus IFG and the 195 participants with isolated IGT

${ }^{\mathrm{b}} p$ values refer to IGT vs NGT I, insulin; G, glucose; $\mathrm{S}_{\mathrm{I}}$, insulin sensitivity during FSIVGTT; ISR, insulin secretory rate; AIR, acute insulin response during FSIVGTT; $\mathrm{S}_{\mathrm{G}}$, glucose sensitivity during the FSIVGTT; FPI, fasting plasma insulin concentration; FPG, fasting plasma glucose concentration; F-NEFA, fasting NEFA concentration

groups $(r=-0.576, p<0.0001)$, within the IGT group ( $r=$ $-0.412, p<0.0001)$ and within the NGT group $(r=-0.299$, $p<0.0001)$. The $2 \mathrm{~h}$ plasma glucose correlated inversely with all insulin secretion measures in the combined NGT/ IGT groups $(n=717)$ and in the IGT group $(n=602)$, after correction for age, BMI and sex (ESM Table 1). However, $\Delta \mathrm{ISR}_{0-120} / \Delta \mathrm{G}_{0-120}$ and $\Delta \mathrm{ISR}_{0-120} / \Delta \mathrm{G}_{0-120} \times$ Matsuda index displayed the strongest correlation with $2 \mathrm{~h}$ plasma glucose in the combined IGT/NGT group ( $r=-0.578, p<0.0005$ and $r=-0.424, p<0.0005)$ (ESM Table 1 and Fig. $3 \mathrm{~d}$ ).

Correlation between $2 \mathrm{~h}$ plasma glucose and insulin sensitivity (ESM Table 1) In combined IGT/NGT, $2 \mathrm{~h}$ plasma glucose correlated inversely with the Matsuda insulin sensitivity index and positively with hepatic and adipocyte insulin resistance indices $(p<0.0005)$ (ESM Table 1). In IGT alone, $2 \mathrm{~h}$ plasma glucose correlated with the Matsuda index but not with hepatic insulin resistance.

Correlations between FPG and insulin secretion (ESM Table 2) In combined IGT/NGT (ESM Table 2, Fig. 2d), FPG correlated inversely with measures of insulin secre- tion. Similar, but weaker correlations were observed when only IGT was examined. The early insulin response $\left(\Delta \mathrm{I}_{0-30}\right)$ $\Delta \mathrm{G}_{0-30}$ and $\Delta \mathrm{I}_{0-30} / \Delta \mathrm{G}_{0-30} \times$ Matsuda index) during the OGTT was inversely correlated with the FPG in the combined IGT/NGT and IGT groups $(p<0.005$; ESM Table 2). $\Delta \mathrm{I}_{0-120} / \Delta \mathrm{G}_{0-120}$ and $\Delta \mathrm{I}_{0-120} / \Delta \mathrm{G}_{0-120} \times$ Matsuda index were also inversely correlated with FPG $(p<0.005)$ in the combined IGT/NGT groups and in the IGT group alone (ESM Table 2). Reduced AIR (0-10 min) during the FSIVGTT correlated with the increase in FPG in combined IGT/NGT and in IGT (ESM Table 2).

Correlations between FPG and measures of insulin sensitivity (ESM Table 2) FPG correlated inversely with the Matsuda insulin sensitivity index and positively with hepatic and adipocyte insulin resistance indices in the combined IGT/NGT and IGT groups (ESM Table 2).

Correlations between various insulin sensitivity indices The Matsuda insulin sensitivity index correlated positively with $\mathrm{S}_{\mathrm{I}}$ during the FSIVGTT in IGT $(r=0.518, p<0.0001)$. Hepatic insulin resistance correlated with the Matsuda 


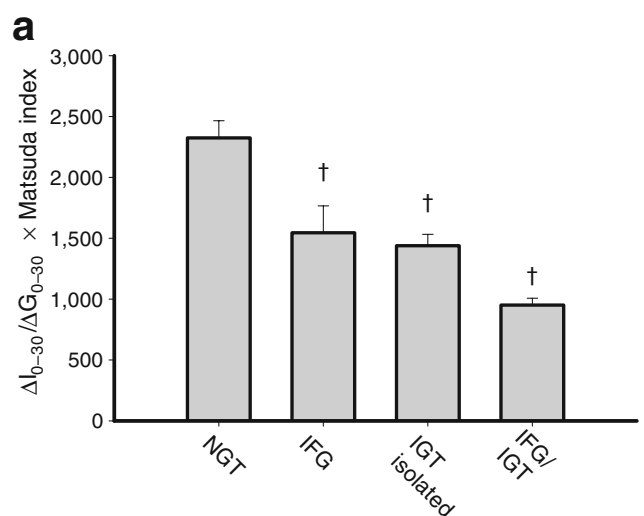

C

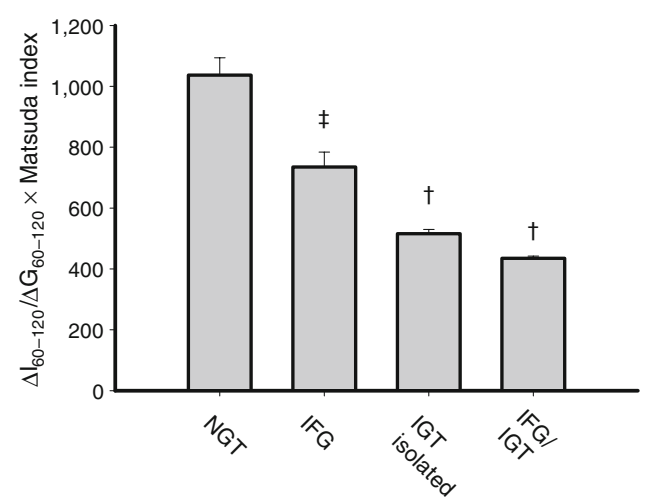

Fig. 2 Insulin secretion/insulin resistance indices $\left(\right.$ a $\Delta \mathrm{I}_{0-30} / \Delta \mathrm{G}_{0-30} \times$ Matsuda index; b $\Delta \mathrm{I}_{0-120} / \Delta \mathrm{G}_{0-120} \times$ Matsuda index; c $\Delta \mathrm{I}_{60-120} / \Delta \mathrm{G}_{60-}$ ${ }_{120} \times$ Matsuda index) in participants with NGT, isolated IGT, isolated IFG and combined IGT/IFG. The $p$ values refer to comparisons with

index in the combined IGT/NGT $(r=-0.938, p<0.0001)$ and IGT $(r=-0.934, p<0.0001)$ groups. Adipocyte insulin resistance correlated with $\mathrm{S}_{\mathrm{I}}(r=-0.425, p<0.0001)$, Matsuda index $(r=-0.833, p<0.0001)$ and hepatic insulin resistance $(r=0.867, p<0.0001)$ in IGT.

Correlations between various insulin secretion indices The early insulinogenic index $\left(\Delta \mathrm{I}_{0-30} / \Delta \mathrm{G}_{0-30}\right)$ during the OGTT correlated positively with AIR during the FSIVGTT in IGT $(r=0.598, p<0.0001)$.

Correlations with glucose sensitivity Impaired glucosemediated glucose uptake $\left(\mathrm{S}_{\mathrm{G}}\right)$ during the FSIVGTT correlated $(r=0.294, p<0.0001)$ with reduced AIR $(0$ $10 \mathrm{~min})$ during the FSIVGTT $\left(\Delta \mathrm{I}_{0-10}\right)$.

Contribution of impaired insulin secretion and insulin resistance to $2 \mathrm{~h}$ plasma glucose If NGT participants with $2 \mathrm{~h}$ plasma glucose $<5.55 \mathrm{mmol} / \mathrm{l}$ are taken as $100 \%$ of normal, both insulin secretion and insulin sensitivity declined progressively with increasing $2 \mathrm{~h}$ plasma glucose (Fig. 4). However, at all $2 \mathrm{~h}$ plasma glucose concentrations,
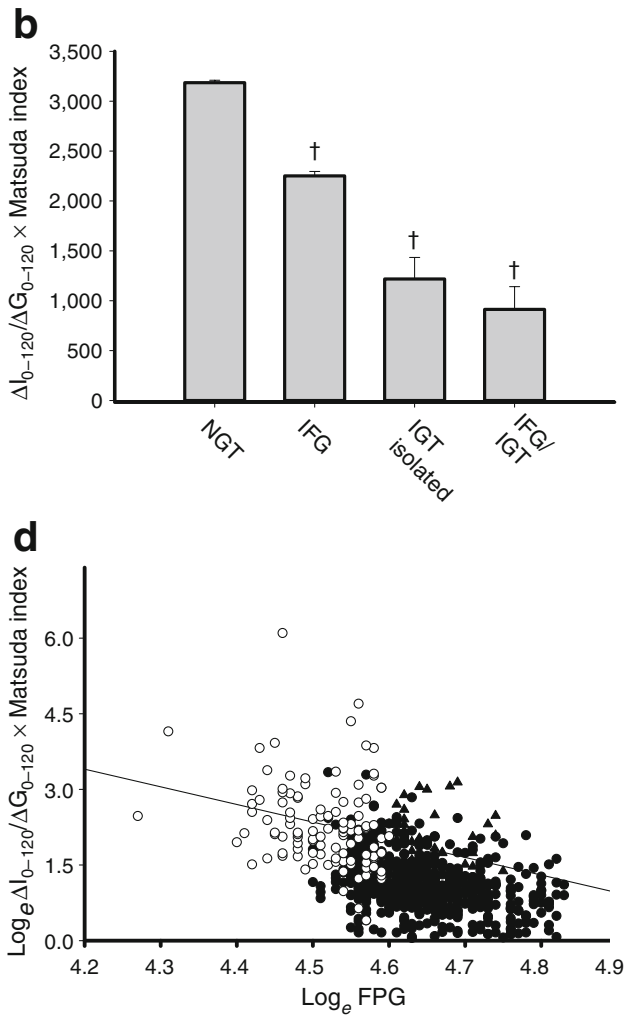

NGT. d $\log _{e}$ of insulin secretion/insulin resistance index plotted against $\log _{e}$ of $2 \mathrm{~h}$ plasma glucose in participants with NGT (white circles), IFG (black triangles) and all IGT (black circles) $(r=-0,512$, $p<0.0005) .{ }^{\dagger} p<0.00005,{ }^{\ddagger} p<0.005$

the decline in insulin secretion was two- to threefold greater than the decline in insulin sensitivity.

Multivariate analysis To evaluate the contributions of beta cells, muscle, liver and fat to the incremental glucose AUC during the OGTT, we performed multiple regression analysis using measures of insulin secretion $\left(\Delta \mathrm{I}_{0-120} / \Delta \mathrm{G}_{0-120} \times\right.$ Matsuda index), insulin sensitivity (Matsuda index), hepatic insulin resistance and adipocyte insulin resistance as independent variables and the incremental glucose AUC as the dependent value (Table 3). Beta cell function was the primary determinant of the glucose AUC, explaining $62 \%$ of the variance. Whole body (primarily reflects muscle) and liver insulin resistance contributed an additional $4 \%$ to the glucose AUC, giving $r^{2}=0.665$ and explaining $66 \%$ of the variation.

\section{Discussion}

ACT NOW is a prospective, double-blind, randomised, placebo-controlled study to examine the ability of pioglita- 
a

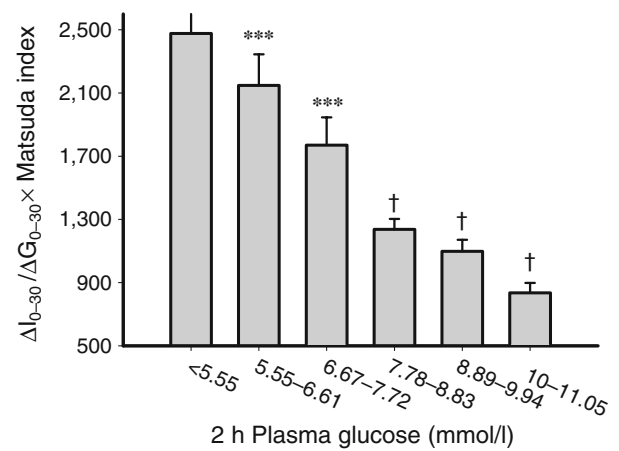

C

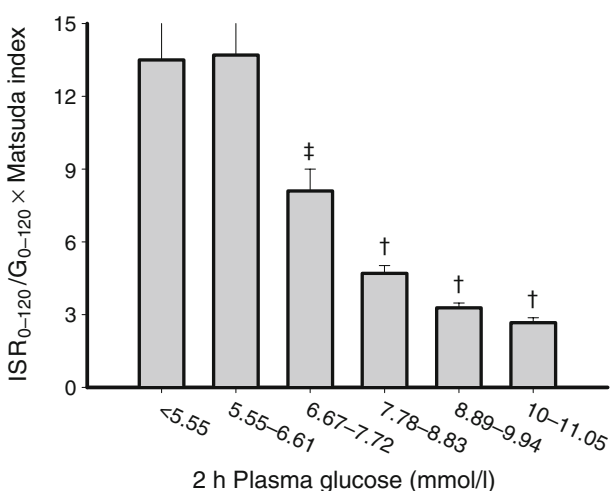

Fig. 3 Insulin secretion indices related to the $2 \mathrm{~h}$ plasma glucose concentration: a $\Delta \mathrm{I}_{0-30} / \Delta \mathrm{G}_{0-30} \times$ Matsuda index; b $\Delta \mathrm{I}_{0-120} / \Delta \mathrm{G}_{0-120} \times$ Matsuda index; c $\Delta \mathrm{ISR}_{0-120} / \Delta \mathrm{G}_{0-120} \times$ Matsuda index. The $p$ values refer to comparisons with the group with the lowest $2 \mathrm{~h}$ plasma

zone to prevent the progression of IGT to type 2 diabetes. During screening, we also identified 115 NGT and 50 IFG participants. When analysed collectively, the characteristic Starling curve of the pancreas [6] relating FPG to the mean insulin response during the OGTT was observed (Fig. 1c). Despite a similar FPG $(5.8 \mathrm{mmol} / \mathrm{l})$, IGT participants had worse glucose tolerance than IFG participants (Fig. 1). The early (30 min) plasma insulin response was similar in IGT and NGT, but the total $(0-120 \mathrm{~min})$ plasma insulin response and insulin secretory rate (ISR) were significantly higher in IGT than in NGT (Fig. 1b, Table 2). Beta cells respond to an increment in glucose with an increment in insulin and this response is modulated by the severity of insulin resistance $[19,22,24]$. Thus, the gold standard for beta cell function is the IS/IR (disposition) index [19, 22, 24, 25]. For the $0-30$ and $0-120$ min periods, the IS/IR index was markedly reduced in IGT vs NGT (Table 2, Fig. 2a, b and ESM Fig. 1c). If the $2 \mathrm{~h}$ plasma glucose during the OGTT is used as the measure of glucose tolerance (Fig. 3), early $(0-30 \mathrm{~min})$ and total $(0-120 \mathrm{~min}) \mathrm{IS} / \mathrm{IR}$ indices declined markedly with increasing $2 \mathrm{~h}$ plasma glucose. Individuals in the upper tertile of IGT $(2 \mathrm{~h}$ plasma glucose $10.0-11.05 \mathrm{mmol} / \mathrm{l})$ lost $75-80 \%$ of their beta cell function

\section{b}

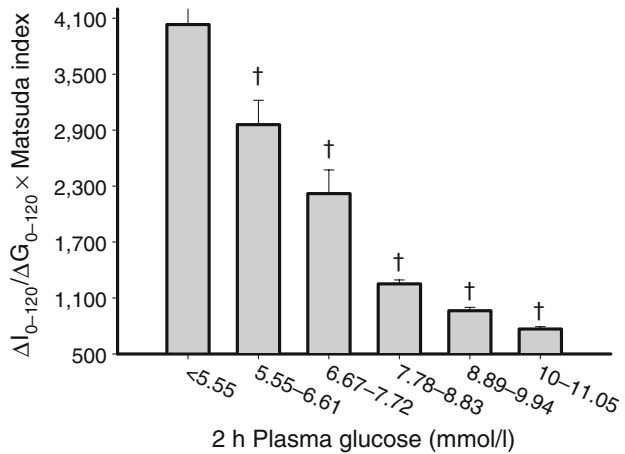

d

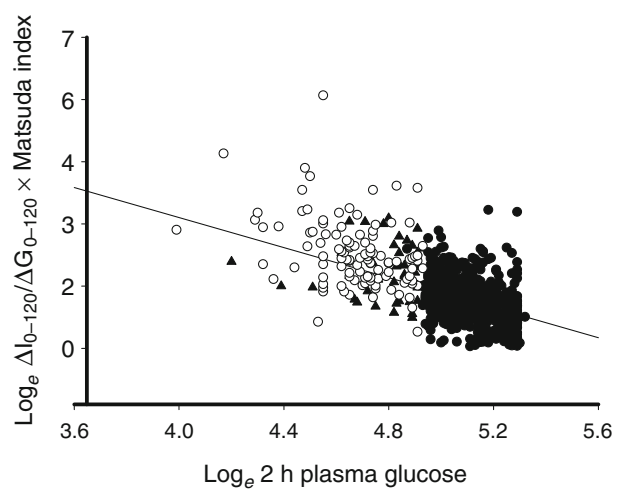

glucose concentration. d $\log _{e}$ of $\Delta \mathrm{I}_{0-120} / \Delta \mathrm{G}_{0-120} \times$ Matsuda index plotted against $\log _{e}$ of $2 \mathrm{~h}$ plasma glucose in participants with NGT (white circles), IFG (black triangles) and all IGT (black circles) $(r=$ $-0.623, p<0.0005) .{ }^{\dagger} p<0.0005, * * * p<0.001,{ }^{\star} p<0.005$

(Fig. 3c and ESM Fig. 1c). Within the NGT range, the IS/IR index $\left(\Delta \mathrm{I}_{0-120} / \Delta \mathrm{G}_{0-120} \times\right.$ Matsuda index and $\Delta \mathrm{ISR}_{0-120} /$ $\Delta \mathrm{G}_{0-120} \times$ Matsuda index) declined by $\sim 50 \%$ as $2 \mathrm{~h}$ plasma glucose increased from $<5.5$ to $7.7 \mathrm{mmol} / \mathrm{l}$ (Fig. 3b, c). These observations are consistent with previous results

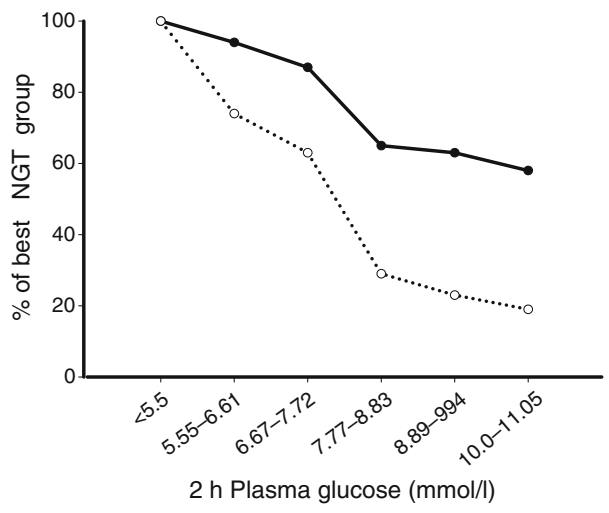

Fig. 4 Plot of beta cell function (insulin secretion/insulin resistance index $\left[\Delta \mathrm{I}_{0-120} / \Delta \mathrm{G}_{0-120} \times\right.$ Matsuda index $]$ ) and insulin sensitivity (Matsuda index) against $2 \mathrm{~h}$ plasma glucose. Data are percentages of the best NGT group $(2 \mathrm{~h}$ glucose $<5.5 \mathrm{mmol} / \mathrm{l})$. Black circles, Matsuda index of insulin sensitivity; white circles, $\Delta \mathrm{I}_{0-120} / \Delta \mathrm{G}_{0-120} \times$ Matsuda index 
Table 3 Stepwise multiple regression analysis in all participants, using the incremental glucose AUC during the OGTT as the dependent variable

\begin{tabular}{|c|c|c|}
\hline & $\begin{array}{l}\text { Partial } \\
\text { correlation } \\
\text { coefficient }\end{array}$ & $\begin{array}{l}\text { Final model } \\
\text { increase } \\
\text { in multiple } r^{2}\end{array}$ \\
\hline \multicolumn{3}{|l|}{ Glucose $\mathrm{AUC}_{0-120}$} \\
\hline \multicolumn{3}{|l|}{ Insulin secretion } \\
\hline$\Delta \ln \mathrm{I}_{0-120} / \Delta \mathrm{G}_{0-120} \times$ Matsuda index & $-0.786^{* * *}$ & 0.618 \\
\hline \multicolumn{3}{|l|}{ Insulin sensitivity } \\
\hline Whole-body Matsuda index & $-0.136^{*}$ & 0.006 \\
\hline Liver $(\mathrm{FPI} \times \mathrm{FPG})$ & $-0.345^{*}$ & 0.041 \\
\hline Adipocytes (FPI×F-NEFA) & 0.062 & NS \\
\hline Total $r^{2}$ & & 0.665 \\
\hline
\end{tabular}

Adipocyte insulin resistance $($ FPI $\times$ F-NEFA) did not contribute significantly to the model

${ }^{a}$ Variables included in the multiple regression analysis and their respective contribution to the value of multiple $r^{2}$

$* p<0.05, * * * p<0.001$

from our group [19, 20, 25, 26] and others [27]. If the $\log _{e}$ of the IS/IR index is plotted against $\log _{e}$ of $2 \mathrm{~h}$ plasma glucose (Fig. 3d) or $\log _{e}$ of FPG (Fig. 2d), an inverse linear relationship is observed $(r=-0.623, p<0.00001$ and $r=-0.512, p<0.0001)$, indicating that progressive loss of beta cell function is the major determinant of glucose intolerance as individuals pass from NGT to IGT.

Impaired fasting glucose Individuals with IFG and IGT (Fig. 1a) had similar increases in FPG (5.8 mmol/l) and initial (0-30 min) plasma glucose during the OGTT. However, after $60 \mathrm{~min}$ the plasma glucose plateaued and then declined in IFG, attaining values similar to those in NGT at $120 \mathrm{~min}$. In contrast, in IGT, plasma glucose continued to increase after $30 \mathrm{~min}$ and remained elevated at 120 min (Fig. 1). These plasma glucose profiles are, in large part, determined by the health of the beta cell. Thus, while the IS/IR index $(\Delta \mathrm{I} / \Delta \mathrm{G} \times$ Matsuda index $)$ from 0 to 30 min was similarly reduced $(p<0.01)$ in both IFG and IGT (Fig. 2a), the IS/IR index from 60 to 120 min was only modestly decreased in IFG but markedly reduced in IGT $(p<0.01$ vs IFG; $p<0.0005$ vs NGT), with an even greater reduction in combined IGT/IFG (Fig. 2c). In IGT, wholebody insulin sensitivity (Matsuda index) was reduced by $50 \%$ (Table 2) and contributed to the elevated $2 \mathrm{~h}$ plasma glucose (Table 1). Whole-body insulin sensitivity was less severely reduced in IFG (Table 2) and, in the presence of only modestly reduced beta cell function, resulted in a $2 \mathrm{~h}$ plasma glucose $(6.7 \pm 0.1 \mathrm{mmol} / \mathrm{l})$ that was only slightly higher than in NGT $(6.0 \pm 0.11 \mathrm{mmol} / \mathrm{l})$. Thus, the pathophysiological mechanisms responsible for IGT and IFG differ considerably. People with IFG have mild whole-body insulin resistance and impaired early (0-30 min) but nearnormal late (60-120 min) insulin secretion. People with IGT have severe defects in both early and late insulin responses and moderate to severe insulin resistance [19, 20].

Natural history of beta cell dysfunction and insulin resistance If $2 \mathrm{~h}$ plasma glucose $<5.5 \mathrm{mmol} / 1$ is considered normal, NGT participants with $2 \mathrm{~h}$ plasma glucose $6.67-$ $7.7 \mathrm{mmol} / 1 \mathrm{had}$ a $40 \%$ decrease in the IS/IR index, while individuals in the upper tertile of IGT (10-11.05 $\mathrm{mmol} / \mathrm{l})$ had an $80 \%$ decrease in the IS/IR index (Fig. 3b, c). Insulin sensitivity declined by $34 \%$ in NGT participants with $2 \mathrm{~h}$ plasma glucose $6.67-7.7 \mathrm{mmol} / 1$ and by $42 \%$ in participants in the upper tertile of IGT (10.0-11.05 mmol/l). From the pathophysiological standpoint $(80 \%$ decline in beta cell function; $42 \%$ decline in insulin sensitivity), individuals with IGT who were in the upper tertile of glucose intolerance should be considered to have diabetes. Moreover, in the Diabetes Prevention Program $~ 13 \%$ of IGT individuals had background retinopathy [28]. The present results, based upon pathophysiology combined with clinical evidence (retinopathy in IGT), indicate that diabetes starts much earlier than is diagnosed based on current diagnostic criteria [15].

Insulin sensitivity In NGT and IGT, the Matsuda insulin sensitivity index declined as $2 \mathrm{~h}$ plasma glucose increased from $<5.5$ to $7.7 \mathrm{mmol} / 1$ (i.e. within the NGT range) to increasing IGT tertiles $(r=-0.271, p<0.0001)$ (ESM Fig. 3). $\mathrm{S}_{\mathrm{I}}$ correlated inversely with the Matsuda index $(r=-0.518$, $p<0.001)$. Using the insulin clamp, we $[19,20,25,26]$ and others [29, 30] have shown that persons with IGT are resistant to insulin. The present results suggest that, within the NGT to IGT range, the OGTT-derived Matsuda index may be more sensitive than $\mathrm{S}_{\mathrm{I}}$ in detecting changes in insulin sensitivity. Of note, Xiang et al. reported that $\mathrm{S}_{\mathrm{I}}$ became less discriminatory at low insulin sensitivity levels [31].

Summary: insulin secretion/sensitivity The ability of beta cells to respond to oral glucose deteriorates markedly within the NGT range and with progression to IGT (Figs 3, 4). When expressed as percentage of the best NGT group, for any given $2 \mathrm{~h}$ plasma glucose the decline in beta cell function was 2- to 3-fold greater than the reduction in insulin sensitivity (Fig. 4). For every $0.5 \mathrm{mmol} / 1$ increase in $2 \mathrm{~h}$ plasma glucose above $5.5 \mathrm{mmol} / 1$, there was a $4.5 \%$ decrease in insulin sensitivity and an $8.7 \%$ decrease in insulin secretion over the NGT to IGT range (5.5 to $11.05 \mathrm{mmol} / \mathrm{l})$.

Aetiology of beta cell dysfunction Progressive beta cell failure can be genetic or acquired (lipotoxicity, glucotoxicity glucose-like peptide-1/gastric inhibitory polypeptide 
deficiency or resistance, etc.). Both fasting ( $r=-0.118, p<$ $0.05)$ and post-OGTT $(r=-0.302, p<0.005)$ plasma NEFA correlated inversely with decreased beta cell function $(\Delta \mathrm{ISR} / \Delta \mathrm{G} \times$ Matsuda index) in the combined NGT/IGT group, and Kashyap et al. [32] have shown that increased NEFA inhibits first- and second-phase insulin secretion.

Both fasting (ESM Table 2) and $2 \mathrm{~h}$ (ESM Table 1) plasma glucose correlated inversely with all measures of insulin secretion, especially with the IS/IR index. With regard to glucotoxicity, an increase in mean day-long plasma glucose of only $0.9 \mathrm{mmol} / \mathrm{l}$ in partially pancreatectomised NGT rats caused a marked deterioration in insulin secretion [33]. Conversely, plasma glucose reduction in diabetic rodents with renal glucose transport inhibitors normalised insulin secretion [34]. Our NGT participants in the top tertile of oral glucose tolerance were presumably exposed to significant around-the-clock hyperglycaemia compared with those in the bottom tertile.

Age, obesity and fat distribution influence the insulin secretion/insulin sensitivity index. After correction for age, BMI and waist circumference, relationships of insulin secretion and insulin sensitivity with fasting and $2 \mathrm{~h}$ plasma glucose in NGT and IGT remained unchanged. Increasing BMI $(r=-0.401, p<0.005)$ and waist circumference $(r=$ $-0.423, p<0.0005)$ were correlated with the Matsuda insulin sensitivity index and $\mathrm{S}_{\mathrm{I}}$. IGT individuals with one or more first-degree relatives with diabetes were more insulin-resistant than those without a family history of diabetes $(5.23 \pm 0.21$ vs $3.61 \pm 0.30, p<0.005)$. Age, obesity and fat distribution had no effect on the IS/IR index. While insulin secretion increased in obese individuals as a function of insulin resistance, the IS/IR index was similar in lean and obese NGT and IGT participants. Thus, beta cells in obese individuals respond similarly to beta cells in lean individuals after insulin resistance was accounted for.

Multivariate analysis Beta cell function, whole-body insulin sensitivity and hepatic insulin resistance were independent predictors of the glucose AUC during the OGTT and explained $66 \%$ of the variation (Table 3); anthropometric and ethnofamilial traits had little effect. Thus, oral glucose tolerance is largely determined by the metabolic phenotype: by beta cell dysfunction and insulin resistance.

Study limitations The study was cross-sectional and caution should be employed when extrapolating the results of such studies to the natural history of IGT. However, changes within groups and from one group to another (NGT to IGT) were robust and consistent with other prospective studies [6, 29-31]. The OGTT has some inherent variability. Because of the large numbers of participants in each group, this variability should be mostly negated. Importantly, the AIR and $\mathrm{S}_{\mathrm{I}}$ (FSIVGTT) yielded results similar to those obtained with the OGTT. The IS/IR index contains some redundancy since insulin appears in the measure of insulin secretion and insulin sensitivity. Use of the C-peptide to calculate ISR obviates this concern. Because insulin secretion declines dramatically with increasing $2 \mathrm{~h}$ plasma glucose while insulin resistance may be less closely related to glucose tolerance, the impact of impaired insulin action may be underestimated.

Conclusion Although this study was cross-sectional, the results show that glucose intolerance is a continuum and declines progressively throughout the entire range of NGT and IGT (Figs 3,4). The two major pathophysiological disturbances - insulin resistance and beta cell dysfunctiondeclined progressively over the range of NGT and IGT. Participants in the upper tertile of IGT lost $\sim 80 \%$ of their beta cell function compared with participants with NGT. We speculate that the establishment of defined glucose cut-off points for the diagnosis of IGT and type 2 diabetes are somewhat arbitrary and need to be re-evaluated on the basis of our current understanding of pathophysiology.

Acknowledgements The authors thank our volunteers, who participated selflessly in this study. We are grateful to our nurses and support staff for their effort in recruitment and follow-up of participants and for their assistance in performing the multiple studies described here. This investigator-initiated study was supported by a grant from Takeda Pharmaceuticals.

Conflict of interest R. A. DeFronzo is on the advisory boards of Takeda, Amylin, Eli Lilly, Roche, Novartis, Johnson and Johnson and Bristol Meyers Squibb. R. A. DeFronzo has grant support from Takeda, Amylin, Eli Lilly, Roche, Novartis, BMS, Merck and Pfizer, is a member of the speakers bureau of Takeda, Eli Lilly and Amylin, and is a consultant for Takeda, Amylin, Eli Lilly, Roche, Novartis and BMS. S. Mudaliar has grant support from GSK, sanofi-aventis and Intercept Pharm. R. R. Henry has grant support from Amylin, Biodel, BMS, GSK, Keryx, Lifescan, Eli Lilly, Merck, Novartis, Novo, Pfizer, Roche, Sankyo and Veralight, is a consultant for Amylin, Astra Zeneca, BMS, Diobex, GSK, Isis, Eli Lilly, Merck, Novartis, Novo, Roche, Sankyo, sanofi-aventis and Takeda, and is a member of the speakers bureau of Amylin, GSK and Eli Lilly. N. Musi has no conflicts of interest to declare. M. A. Banerji has research grants from Novartis, Takeda and Pfizer, is a consultant for BMS and Boehringer Ingelheim, and is a speaker for Novartis, Takeda, Pfizer, Merck and sanofiaventis. R. Ratner has grant support from AstraZenica, Bayhill Therapeutics, Boehringer Ingelheim, GSK, Merck, Pfizer, Takeda and Veralight, is on the Advisory Board of Amylin, AstraZenica, Eli Lilly, GSK, Lifescan, NovoNordisk, sanofi-aventis, Takeda and Tethys Bioscience, and owns stock in Merck, Johnson \& Johnson and Abbott. F. D. Stentz. has no conflict of interest. A. E. Kitabchi is on the Advisory Board for Merck, is a member of the Speakers Bureau for Takeda, and has grant support from Takeda and sanofiaventis. D. C. Schwenke has grant support from Takeda. D. Tripathy has grant support from Takeda. S. Clement has no conflict of interest. T. A. Buchanan has grant support from Takeda and is a member of the speakers bureau and on the advisory board for Takeda. P. Reaven has grant support from Takeda and Amylin/Lilly, and is a member of the speakers bureau for Takeda and Merck. 


\section{References}

1. Cowie CC, Rust KF, Byrd-Holt DD et al (2006) Prevalence of diabetes and impaired fasting glucose in adults in the U.S. population: National Health And Nutrition Examination Survey 1999-2002. Diabetes Care 29:1263-1268

2. World Health Organization, Diabetes Programme Facts and Figures, 2007. World Health Organisation, Geneva. Available from www.who.int/diabetes/facts/en/, accessed 27 October 2009

3. Stratton IM, Adler AI, Neil HAW, UK Prospective Diabetes Study Group et al (2000) Association of glycaemia with macrovascular and microvascular complications on type 2 diabetes (UKPDS 35): prospective observational study. BMJ 321:405-412

4. UK Prospective Diabetes Study (UKPDS) Group (1998) Intensive blood-glucose control with sulphonylureas or insulin compared with conventional treatment and risk of complications in patients with type 2 diabetes (UKPDS 33). Lancet 352:837-853

5. DeFronzo RA (1988) Lilly Lecture 1987. The triumvirate: betacell, muscle, liver. A collusion responsible for NIDDM. Diabetes 37:667-687

6. Weyer C, Bogardus C, Mott DM, Pratley RE (1999) The natural history of insulin secretory dysfunction and insulin resistance in the pathogenesis of type 2 diabetes mellitus. J Clin Invest 104: 787-794

7. Tuomilehto J, Lindstrom J, Eriksson JG et al (2001) Prevention of type 2 diabetes mellitus by changes in lifestyle among subjects with impaired glucose tolerance. N Engl J Med 344:1343-1350

8. Knowler WC, Barrett-Connor E, Fowler SE et al (2002) Reduction in the incidence of type 2 diabetes with lifestyle intervention or metformin. N Engl J Med 346:393-403

9. Gerstein HC, Yusuf S, Bosch J et al (2006) Effect of rosiglitazone on the frequency of diabetes in patients with impaired glucose tolerance or impaired fasting glucose: a randomised controlled trial. Lancet 368:1096-1105

10. Xiang AH, Peters RK, Kjos SL et al (2006) Effect of pioglitazone on pancreatic beta-cell function and diabetes risk in Hispanic women with prior gestational diabetes. Diabetes 55:517-522

11. Group The Diabetes Prevention Program Research (2005) Prevention of type 2 diabetes with troglitazone in the Diabetes Prevention Program. Diabetes 54:1150-1156

12. Chiasson JL, Josse RG, Gomis R, Hanefeld M, Karasik A, Laakso M (2002) Acarbose for prevention of type 2 diabetes mellitus: the STOP-NIDDM randomised trial. Lancet 359:2072-2077

13. Gillies CL, Abrams KR, Lambert PC et al (2007) Pharmacological and lifestyle interventions to prevent or delay type 2 diabetes in people with impaired glucose tolerance: systematic review and meta-analysis. BMJ 334:299-308

14. Kitabchi AE, Temprosa M, Knowler WC et al (2005) Role of insulin secretion and sensitivity in the evolution of type 2 diabetes in the diabetes prevention program: effects of lifestyle intervention and metformin. Diabetes 54:2404-2414

15. Expert Committee on the Diagnosis and Classification of Diabetes Mellitus (2003) Follow-up report on the diagnosis of diabetes mellitus. Diabetes Care 26:3160-3167

16. Bergman RN, Ader M, Huecking K, van Citters G (2002) Accurate assessment of beta-cell function: the hyperbolic correction. Diabetes 51(Suppl 1):S212-S220

17. Van Cauter E, Mestrez F, Sturis J, Polonsky KS (1992) Estimation of insulin secretion rates from C-peptide levels. Comparison of individual and standard kinetic parameters for C-peptide levels.
Comparison of individual and standard kinetic parameters for Cpeptide clearance. Diabetes 41:368-377

18. Matsuda M, DeFronzo RA (1999) Insulin sensitivity indices obtained from oral glucose tolerance testing: comparison with the euglycemic glucose clamp. Diabetes Care 22:1462-1470

19. Abdul-Ghani MA, Jenkinson CP, Richardson DK, Tripathy D, DeFronzo RA (2006) Insulin secretion and action in subjects with impaired fasting glucose and impaired glucose tolerance. Results from the Veterans Administration Genetic Epidemiology Study. Diabetes 55:1430-1435

20. Abdul-Ghani A, Tripathy D, DeFronzo RA (2006) Contributions of b-cell dysfunction and insulin resistance to the pathogenesis of impaired glucose tolerance and impaired fasting glucose. Diabetes Care 29:1130-1139

21. Groop LC, Bonadonna RC, Shank M, Petrides AS, DeFronzo RA (1991) Role of free fatty acids and insulin in determining free fatty acid and lipid oxidation in man. J Clin Invest 87:83-89

22. Bergman RN, Finegood DT, Kahn SE (2002) The evolution of B cell dysfunction and insulin resistance in type 2 diabetes. Eur $\mathrm{J}$ Clin Invest 32:35-45

23. Ahren B, Taborsky GJ (2003) Beta-cell function and insulin secretion. In: Porte D, Sherwin RS, Baron A (eds) Ellenberg and Rifkin's diabetes mellitus. McGraw Hill, New York, pp 43-65

24. DeFronzo RA (2009) From the triumvirate to the ominous octet: a new paradigm for the treatment of type 2 diabetes. Diabetes 58:773-795

25. Gastaldelli A, Ferrannini E, Miyazaki Y, Matsuda M, DeFronzo RA (2004) Beta-cell dysfunction and glucose intolerance: results from the San Antonio metabolism (SAM) study. Diabetologia 47:31-39

26. Ferrannini E, Gastaldelli A, Miyazaki Y, Matsuda M, Mari A, DeFronzo RA (2005) B-cell function in subjects spanning the range from normal glucose tolerance to overt diabetes: a new analysis. J Clin Endocrinol Metab 90:493-500

27. Cnop M, Vidal J, Hull RL et al (2007) Progressive loss of beta-cell function leads to worsening glucose tolerance in first-degree relatives of subjects with type 2 diabetes. Diabetes Care 30:677-682

28. Diabetes Prevention Program Research Group (2007) The prevalence of retinopathy in impaired glucose tolerance and recent-onset diabetes in the Diabetes Prevention Program. Diabet Med 24:137-144

29. Tripathy D, Carlsson M, Almgren P et al (2000) Insulin secretion and insulin sensitivity in relation to glucose tolerance: lessons from the Botnia Study. Diabetes 49:975-980

30. Weyer C, Bogardus C, Pratley R (1999) Metabolic characteristics of individuals with impaired fasting glucose and/or impaired glucose tolerance. Diabetes 48:2197-2203

31. Xiang AH, Wang C, Peters RK, Trigo E, Kjos SL, Buchanan TA (2006) Coordinate changes in plasma glucose and pancreatic betacell function in Latino women at high risk for type 2 diabetes. Diabetes 55:1074-1079

32. Kashyap S, Belfort R, Gastaldelli A et al (2003) A sustained increase in plasma free fatty acids impairs insulin secretion in nondiabetic subjects genetically predisposed to develop type 2 diabetes. Diabetes 52:2461-2474

33. Leahy JL, Bonner-Weir S, Weir GC (1988) Minimal chronic hyperglycemia is a critical determinant of impaired insulin secretion after an incomplete pancreatectomy. J Clin Invest 81: 1407-1414

34. Rossetti L, Smith D, Shulman GI, Papachristou D, DeFronzo RA (1987) Correction of hyperglycemia with phlorizin normalizes tissue sensitivity to insulin in diabetic rats. J Clin Invest 79:1510 1515 